\title{
Dynamics of Bean Dwarf Mosaic Geminivirus Cell-to-Cell and Long-Distance Movement in Phaseolus vulgaris Revealed, Using the Green Fluorescent Protein
}

\author{
M. R. Sudarshana, ${ }^{1}$ H. L. Wang, ${ }^{2}$ W. J. Lucas, ${ }^{2}$ and R. L. Gilbertson ${ }^{1}$ \\ ${ }^{1}$ Department of Plant Pathology, University of California, Davis 95616, U.S.A.; ${ }^{2}$ Section of Plant Biology, \\ Division of Biological Sciences, University of California, Davis 95616, U.S.A. \\ Accepted 9 December 1997.
}

\begin{abstract}
The cell-to-cell and long-distance movement of the bipartite geminivirus, bean dwarf mosaic (BDMV), in Phaseolus vulgaris plants was examined with the noninvasive reporter, the green fluorescent protein (GFP). A modified GFP gene (mGFP4) was inserted into the BDMV DNA-A component in place of the coat protein gene (BDMVAmGFP4), and particle bombardment was used to introduce viral DNA into bean seedlings (radicle and hypocotyl tissues). Fluorescence analysis of GFP expressed from BDMVA-mGFP4 established that particle bombardment introduced viral DNA only into epidermal cells, and the requirement for the DNA-B-encoded proteins (BV1 and BC1) in the cell-to-cell movement of BDMVA-mGFP4. This GFP reporter system was used to follow the viral infection process from the seedling stage throughout the entire plant life cycle. In inoculated hypocotyls, BDMV moved from cell to cell through the cortex and showed a striking phloem tropism. Upon entry into phloem tissues, BDMV moved rapidly toward the root via the longdistance transport system, and toward the shoot apex by a combination of cell-to-cell and long-distance movement. Analysis of GFP distribution in systemically infected tissues revealed that BDMV was restricted to phloem cells in both roots and stems. In systemically infected primary and trifoliolate leaves, BDMV infected phloem cells associated with all vein orders (first through fifth), and the capacity of BDMV to exit from phloem tissue into nonphloem cells was correlated with the stage of plant development. Finally, fluorescence analysis of GFP in reproductive tissues established that BDMV infected flower, pod, and seed-coat tissues, but was excluded from the embryo.
\end{abstract}

Systemic infection of a plant by a virus generally requires replication of the viral genome (RNA or DNA), cell-to-cell movement of some form(s) of the virus in the inoculated leaf (or other organ), and, eventually, long-distance transport of the same or different form(s) of the virus to new sites of infection. Samuel (1934) recognized that movement of tobacco mosaic

Corresponding author: R. L. Gilbertson: Telephone: 1-(530)-752-3163; Fax: 1-(530)-752-5674; E-mail: rlgilbertson@ucdavis.edu tobamovirus (TMV) occurs by a slow, cell-to-cell spread through plasmodesmata, followed by rapid, long-distance transport through the phloem translocation stream. It is now well established that TMV encodes a nonstructural protein, the 30-kDa movement protein (MP), that facilitates viral cellto-cell movement by interacting with plasmodesmata (Carrington et al. 1996; Deom et al. 1987, 1990; Lucas and Gilbertson 1994; Waigmann et al. 1994; Wolf et al. 1989). Direct evidence for the interaction of other viral MPs with plasmodesmata has now been provided for the cucumoviruses (Ding et al. 1995), dianthoviruses (Fujiwara et al. 1993), geminiviruses (Noueiry et al. 1994), and the potyviruses (Rojas et al. 1997). The capacity of plant viruses to interact with plasmodesmata to facilitate entry into and exit from different tissue types, particularly those associated with the vasculature, may determine whether a particular virus can systemically infect a given plant species (Carrington et al. 1996; Gilbertson and Lucas 1996; Séron and Haenni 1996). Thus, developing an understanding of the cellular and molecular determinants involved in cell-to-cell and long-distance movement of viruses will provide important insight into viral host specificity as well as aspects of the trafficking of viral and endogenous macromolecular complexes in plants.

Geminiviruses are small, single-stranded (ss) DNA viruses that replicate in the nucleus. The bipartite members of the Geminiviridae family have their genome divided between two approximately 2.6-kb DNA components, referred to as DNA$\mathrm{A}$ and DNA-B. Essential viral functions are partitioned between the two DNA components, with replication and encapsidation encoded on DNA-A, and movement functions and host range and symptom determinants encoded on DNA-B. Genetic studies have shown that both DNA-B-encoded proteins, BC1 (BL1) and BV1 (BR1), are necessary for systemic infection (Brough et al. 1988; Etessami et al. 1988), whereas similar studies have established that the coat protein (AV1) is not required for systemic infection (Azzam et al. 1994; Gardiner et al. 1988; Ingham et al. 1995; Padidam et al. 1995; Sudarshana et al. 1996). Bean dwarf mosaic geminivirus (BDMV) is a typical bipartite geminivirus (Hidayat et al. 1993), and thus requires functional BC1 and BV1 proteins to systemically infect its common bean (Phaseolus vulgaris L.) host (Noueiry et al. 1994). Studies with Escherichia coli- 
expressed BDMV $\mathrm{BC} 1$ and $\mathrm{BV} 1$ proteins have established that the $\mathrm{BC} 1$ protein facilitates cell-to-cell movement of double-stranded (ds) viral DNA, whereas the BV1 protein is involved in export of both ss and ds viral DNA from the nucleus (Noueiry et al. 1994). Although the requirement for functional $\mathrm{BC} 1$ and BV1 proteins in BDMV cell-to-cell movement was predicted based on the distinct properties established for these proteins, this has not been experimentally demonstrated. Studies conducted with another bipartite geminivirus, squash leaf curl (SqLCV), have also established that the BV1 and $\mathrm{BC} 1$ proteins are essential for systemic infection, but it has been proposed that these proteins are involved in cell-to-cell movement of ssDNA (reviewed by Sanderfoot and Lazarowitz 1996). Regardless, the capacity, if any, of bipartite geminiviruses lacking either a functional $\mathrm{BC} 1$ or $\mathrm{BV} 1$ protein to move cell to cell has not been established, nor has the capacity of the DNA-A component to facilitate its own cell-to-cell movement. The latter point is particularly intriguing given reports that DNA-A components of certain bipartite geminiviruses, including BDMV, are capable of systemically infecting plants when delivered by agroinoculation (Klinkenberg and Stanley 1990; Evans and Jeske 1993; Hou et al. 1998).

Bipartite geminiviruses are generally considered to be phloem-limited viruses. However, a recent study demonstrated that BDMV is not phloem-limited in infected common bean or Nicotiana benthamiana (Domin) plants during the early stages of plant development (Wang et al. 1996). This study also identified the existence of viral infection domains within specific organs; e.g., a nonvascular domain that included leaf bundle sheath, mesophyll, and epidermal cells, and a vascular domain comprising the phloem and protophloem cells. However, the immunolocalization methods used in this study are laborious and time-consuming, which limits the amounts of tissue and plants that can be examined and, thus, the ability to follow the viral infection process throughout the life cycle of the plant. The development of the green fluorescent protein (GFP) as a reporter gene (Chalfie et al. 1994) has provided an effective means to follow the cell-to-cell or long-distance movement of a number of RNA viruses (Baulcombe et al. 1995; Epel et al. 1996; Oparka et al. 1995; Padgett et al. 1996; Santa Cruz et al. 1996; Roberts et al. 1997; Rao 1997; Canto et al. 1997), but has yet to be used as a reporter for a DNA virus.

In the present study, we constructed an infectious BDMV DNA-A clone containing a modified form of the GFP gene (mGFP4) in place of the coat protein (CP) gene. Using fluorescence analysis of expressed GFP, we examined the role of the BDMV BV1 and BC1 MPs in cell-to-cell movement, as well as the pathway followed by the virus during long-distance movement. Using this system, we were able to follow the infection process of BDMV throughout the complete life cycle of the common bean plant. These studies revealed the association of the virus with cells of the phloem throughout the systemic infection process, and demonstrated the influence of plant development on viral movement into nonphloem cells.

\section{RESULTS}

Construction of BDMVA-mGFP4, its replication, and GFP expression in protoplasts.

The mGFP4 gene (Haseloff et al. 1997) was inserted in place of the $C P$ gene in an infectious BDMV DNA-A clone, placing the expression of mGFP4 under the control of the $\mathrm{CP}$ promoter and terminator (Fig. 1). A tandem 1.5-mer of the BDMVA-mGFP4 construct was made to facilitate plant inoculations. Protoplasts prepared from a Nicotiana tabacum L. cv. Xanthi nc cell suspension culture were electroporated with monomers or 1.5-mers of BDMVA-mGFP4 or wild-type BDMV-A, and analyzed for GFP expression with a UVfluorescence microscope. Expression of GFP was detected approximately $16 \mathrm{~h}$ post-electroporation of BDMVA-mGFP4 (Fig. 2A), whereas no expression of GFP was detected in protoplasts electroporated with wild-type BDMV-A, or protoplasts electroporated in the presence of buffer only. These experiments established the capacity of the BDMVA-mGFP4 construct to express GFP in plant cells.

Replication of viral DNA in protoplasts transfected with BDMVA-mGFP4 or wild-type BDMV-A 1.5-mers was examined by Southern blot hybridization analysis with a BDMV-A probe. For both constructs, newly replicated viral DNA forms were detected in the cells approximately 3 days post-electroporation. As illustrated in Figure 2B, the replication of BDMVA-mGFP4 was slightly reduced, compared with that of wild-type BDMV-A. These results established that the modifications made in BDMV-A to generate BDMVA-mGFP4 had only a minimal effect on viral replication efficiency in plant cells.

Symptom development in inoculated common bean plants. Bean seedlings were coinoculated with 1.5-mers of BDMVA-mGFP4 and BDMV-B, or 1.5-mers of BDMV-A and BDMV-B (Hou et al. 1998), by particle bombardment (Paplomatas et al. 1994). Consistent with results of an earlier study in which BDMV monomers were used as inoculum (Gilbertson et al. 1991), primary leaves of bean plants that developed from seedlings inoculated with BDMV-A and BDMV-B 1.5-mers developed epinasty, chlorotic spots, and distorted and enlarged veins 5 to 7 days post inoculation (dpi). Primary leaves of plants that developed from seedlings inoculated with BDMVA-mGFP4 and BDMV-B also developed symptoms 5 to $7 \mathrm{dpi}$, albeit similar but less severe in nature (e.g., reduced levels of epinasty, fewer chlorotic spots, and an overall irregular distribution of symptoms). Newly emerged trifoliolate leaves of plants infected by BDMV-A and BDMV-B were stunted and distorted, and overall plant growth was considerably reduced. Trifoliolate leaves of plants infected by BDMVAmGFP4 and BDMV-B displayed symptoms that were similar, but slightly attenuated, compared with those in plants infected by wild-type BDMV. These results confirmed that BDMVAmGFP4, in combination with BDMV-B, was able to systemically infect bean plants. Thus, this GFP construct had the potential to be used as a reporter for BDMV infection.

\section{Cell-to-cell movement of BDMVA-mGFP4 at inoculation sites of bean hypocotyls.}

Bean seedlings were coinoculated with BDMVA-mGFP4 and BDMV-B (hereafter referred to as BDMV-GFP) to determine the cellular pathway utilized during infection of the bean hypocotyl. To detect and monitor BDMV-GFP infection, the surface of inoculated hypocotyls was examined at regular intervals $(4,8,12,16,24,36$, and 48 h post-inoculation [hpi]) with a confocal laser scanning microscope (CLSM). GFP expression was first detected at 8 to $12 \mathrm{hpi}$ in single epidermal 
cells (Fig. 3A). By 16 hpi, cell-to-cell movement of BDMVGFP was detected based on the appearance of GFP in clusters of 3 to 6 epidermal cells (Fig. 3B). By 24 to 48 hpi, BDMVGFP had continued to move, cell to cell, within the epidermis (Fig. 3C and D), and it had also moved into the underlying cortical cells.

The capacity of the BDMV DNA-A component to mediate its cell-to-cell spread was examined by bombarding bean seedlings with BDMVA-mGFP4. For all time points examined, seedlings bombarded with this construct had GFP confined within single epidermal cells of the hypocotyl (Fig. 3E). However, these experiments did not rule out a role for the $\mathrm{CP}$ in cell-to-cell movement. Therefore, bean seedlings were coinoculated with BDMVA-mGFP4 and wild-type BDMV-A. GFP fluorescence was again confined to single epidermal cells (data not shown). These experiments established that (i) viral DNA was delivered to single epidermal cells with this particle bombardment technique, (ii) in the absence of BDMV-B, the DNA-A component was incapable of cell-to-cell movement, and (iii) free GFP did not move cell to cell through plasmodesmata of cells infected with BDMVA-mGFP4 or BDMVA-mGFP4 and BDMV-A. Moreover, GFP remained in these individual epidermal cells for as long as $6 \mathrm{dpi}$, after which time GFP was no longer detectable (data not shown).

Genetic studies established that both DNA-B-encoded proteins, $\mathrm{BC} 1$ and $\mathrm{BV} 1$, are required for BDMV systemic movement (Noueiry et al. 1994). The requirement of these proteins for BDMV cell-to-cell movement was examined by coinoculating bean seedlings with BDMVA-mGFP4 and either a BC1 frameshift mutant, a BV1 frameshift mutant, or both mutants. As shown in Figure $3 \mathrm{~F}$ and G, GFP was confined to single epidermal cells when BDMVA-mGFP4 was coinoculated with either frameshift mutant. However, when BDMVAmGFP4 was coinoculated with both frameshift mutants, or wild-type BDMV-B, GFP was detected in large clusters of epidermal cells by 48 hpi (Fig. $3 \mathrm{H}$ ). These results established that the $\mathrm{BV} 1$ and $\mathrm{BC} 1$ proteins are required for cell-to-cell movement of BDMVA-mGFP4. To ascertain whether the BDMV CP could potentiate the cell-to-cell movement of BDMVA-mGFP4 in combination with either the BV1 or BC1 frameshift mutant, BDMVA-mGFP4 and wild-type BDMV DNA-A were coinoculated with each mutant. Approximately 16 to $24 \mathrm{hpi}$, GFP fluorescence was detected in clusters of 3 to 6 epidermal cells of hypocotyls of seedlings bombarded with BDMVA-mGFP4, BDMV-A, and the BV1 frameshift mutant (data not shown). Fluorescence remained confined to these cells for the duration of these experiments (6 dpi). However, in seedlings bombarded with BDMVA-mGFP4, BDMV-A, and the $\mathrm{BC} 1$ frameshift mutant, fluorescence was confined to individual cells. These results suggest that the BDMV CP can partially rescue cell-to-cell movement in the absence of the $\mathrm{BV} 1$, but not the $\mathrm{BC} 1$, protein.

To assess whether BDMV cell-to-cell movement could be facilitated by the $\mathrm{BC} 1$ and $\mathrm{BV} 1$ proteins of a different geminivirus, bean seedlings were coinoculated with BDMVAmGFP4 and the DNA-B component of a type II bean golden mosaic geminivirus isolate from Guatemala (BGMV-GA; Gilbertson et al. 1991). BDMV and BGMV-GA are incapable of forming infectious pseudorecombinants (E. Garrido-Ramirez, M. R. Sudarshana, and R. L. Gilbertson, unpublished data). However, 16 to $24 \mathrm{hpi}$, GFP fluorescence was detected in clusters of 3 to 6 epidermal cells of hypocotyls bombarded with BDMVA-mGFP4 and the DNA-B component of BGMVGA. These studies indicate that the BGMV BC1 and BV1 proteins were able to facilitate cell-to-cell movement of BDMVA-mGFP4.

\section{Vascular tropism reflected in cortical cell-to-cell movement.}

The cellular pathway for viral entry into the phloem of inoculated seedlings was identified by following the distribution of GFP expression in seedlings inoculated with BDMV-GFP. To simulate normal growth conditions, inoculated seedlings were planted and maintained under controlled environment conditions. Approximately 2 to $3 \mathrm{dpi}$, bright green fluorescent spots could be observed on hypocotyls when examined with a long-wavelength UV lamp. Numerous such infection loci were observed on individual hypocotyls, reflecting discrete inoculation sites resulting from bombardment with gold particles carrying BDMV-GFP DNA. These loci were used to identify appropriate sites to prepare transverse sections. The cellular arrangement of the epidermal, cortical, and vascular tissues of the common bean hypocotyl is shown in Figure 4A. A time course of BDMV-GFP cell-to-cell movement from the epidermis, through the cortex, and into the vascular tissue is presented in Figure 4B-F. By 18 to 24 hpi, BDMV-GFP began to move from the epidermis into the underlying cortical cells (Fig. 4C). The infection front advanced through the cortex toward the vascular cylinder, and appeared to be arrested, temporarily, at the boundary between these two tissues (Fig. 4D).

A significant finding from these experiments was the apparent vascular tropism revealed in this pathway. GFP was observed in a sector of cells ( 7 to 10 cells in width) extending from the epidermis to the vascular boundary (Fig. 4D-F). To determine whether the basis for this vascular tropism might be the delivery of photoassimilates from the cortex to the phloem, experiments were performed in which BDMV-GFPinoculated bean seedlings were grown under light and dark conditions. Preliminary experiments established that a brief interruption to the dark treatment, during the bombardment process, did not induce chlorophyll synthesis (i.e., green pigmentation observed in hypocotyls of light-grown seedlings was absent from hypocotyls of dark-grown seedlings). Thus, the hypocotyl cortex of dark-grown common bean plants could be considered fully heterotrophic in nature. Similar patterns of BDMV-GFP infection were observed for seedlings grown under light and dark conditions. Thus, the basis for the vascular tropism of BDMV-GFP in the bean hypocotyl does not appear to be the flow of photoassimilates from the cortex to the phloem.

BDMV-GFP gained access to the vascular tissue by 2 to 4 dpi (Fig. 4E and F; time points taken at 2 and 4 dpi, respectively). Upon entry into the vascular cylinder, BDMV-GFP spread in a radial direction within the phloem (Fig. 4E-G). Additionally, transverse hypocotyl sections taken 1 to $2 \mathrm{~cm}$ above (acropetal direction) the initial infection site 4 dpi revealed that BDMV-GFP had spread toward the shoot apex within the phloem tissue, but had not re-entered the cortical tissues (Fig. 4H). This most likely reflects cell-to-cell movement within cells of the phloem tissue, because here the direction of long-distance phloem transport should be toward the lower hypocotyl-root regions of the plant. This is sup- 


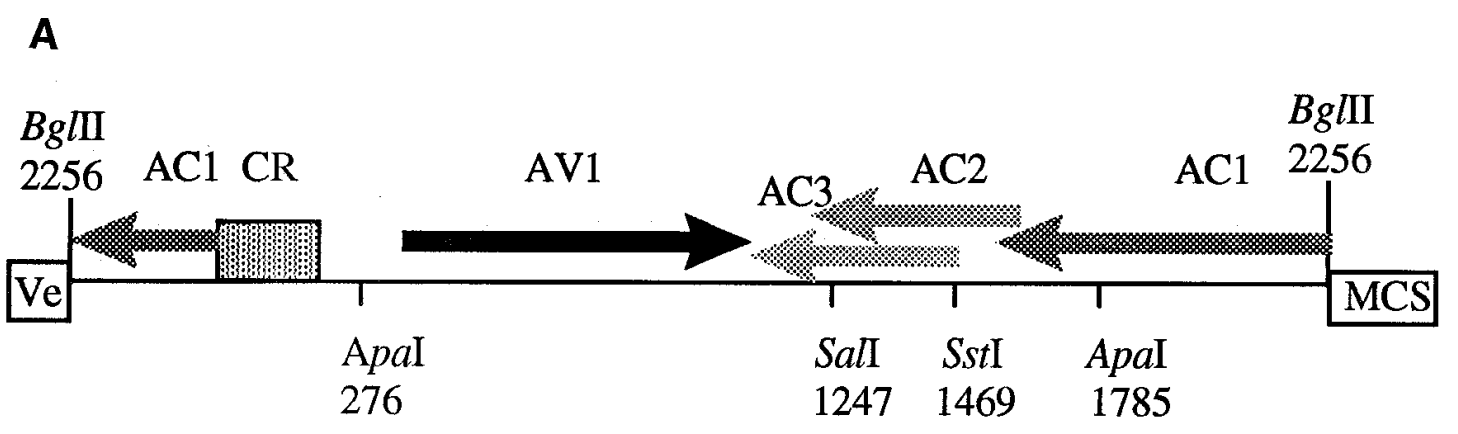

B
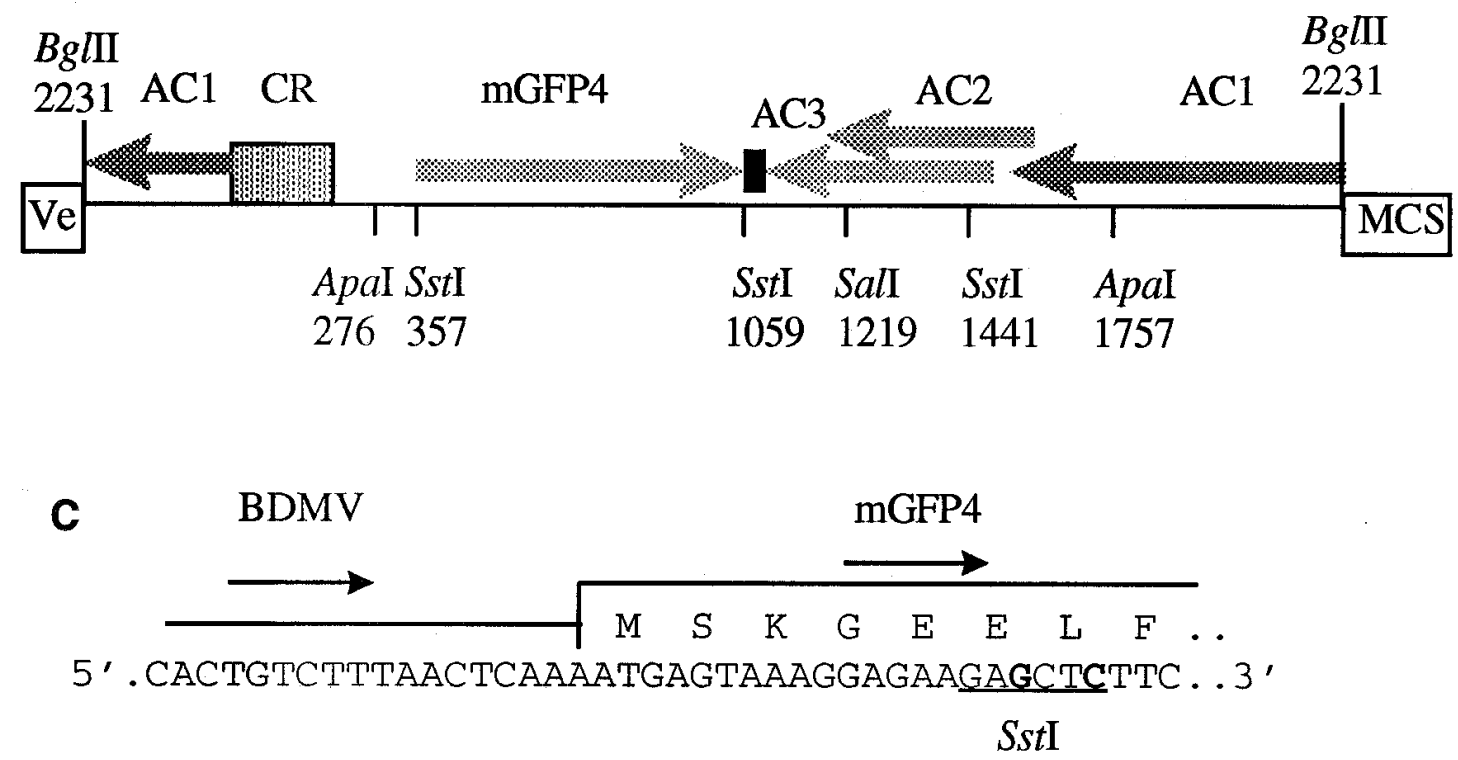

D

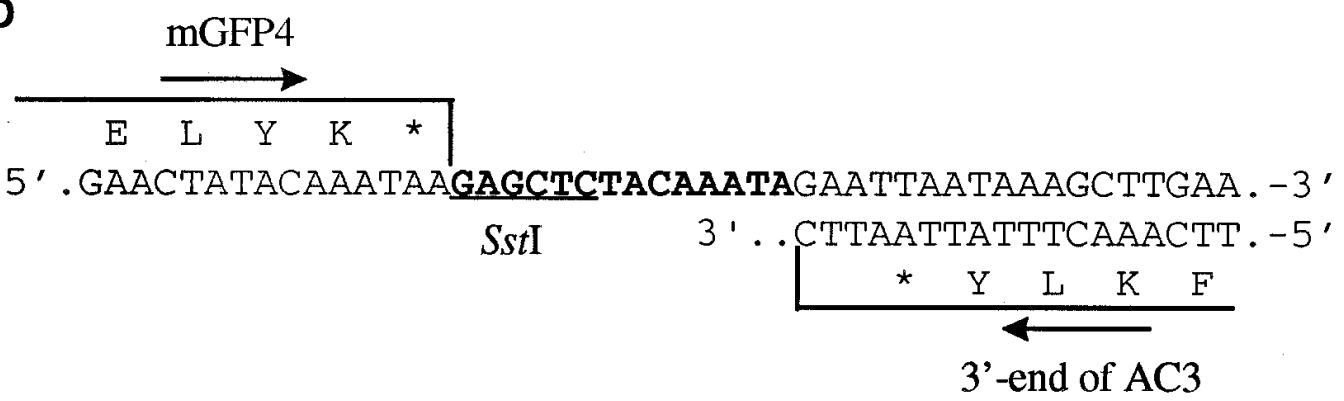

Fig. 1. Schematic illustration of the bean dwarf mosaic geminivirus (BDMV) DNA-A and BDMVA-mGFP4 components used in this study. A, Restriction map of the BDMV DNA-A genome in pBDA1 showing open reading frames (ORFs) and restriction sites used for replacement of the $A V 1$ gene (coat protein [CP]) with the $m G F P 4$ gene. B, Restriction map of the BDMVA-mGFP4 genome showing ORFs and the introduced SstI sites used to insert the $m G F P 4$ gene into the BDMV DNA-A genome. Black box indicates filler sequence inserted between the 3 ' ends of the $m G F P 4$ and $A C 3$ genes (see D). $\mathrm{C}$, Nucleotide sequence of the junction between the CP $5^{\prime}$ noncoding sequence and the initiation codon of the $m G F P 4$ gene. The $S s t \mathrm{I}$ site engineered into the $5^{\prime}$ end of the $m G F P 4$ gene to allow for insertion of the gene into BDMV DNA-A is underlined; the introduced silent mutations are shown in bold. D, Nucleotide sequence of the junction between the $3^{\prime}$ ends of the $m G F P 4$ and $A C 3$ genes. The SstI site engineered into the $3^{\prime}$ end of the $m G F P 4$ gene is underlined; the termination codons of the genes are shown as asterisks. The filler sequence inserted between the $3^{\prime}$ ends of the $m G F P 4$ and $A C 3$ genes is shown in bold. Abbreviations are as follows: CR, common region; MCS, multiple cloning site; Ve, vector sequence. 
ported by the observation that GFP was not detected in similar transverse sections taken 4 to $7 \mathrm{~cm}$ above the initial site of infection (data not shown).

\section{BDMV-GFP long-distance movement.}

To follow the long-distance movement of BDMV-GFP and to identify infection site(s) distant from the point of inoculation, bean seedlings were carefully removed from the soil, sectioned, and examined for GFP with CLSM and fluorescence microscopy. Upon entry into the vascular system, BDMV-GFP was found to move in two directions. By 4 to $5 \mathrm{dpi}$, BDMV-GFP had moved in a basipetal direction because GFP was detected in companion and phloem parenchyma cells within the root, extending into the region of the protophloem (Fig. 5A-C). The distribution of GFP within root tissues suggested that BDMVGFP infection was restricted to the phloem. Thus, the root appears to represent a vascular BDMV infection domain. It is important to note that extensive analysis of sectioned root tissues, from the root tip toward the hypocotyl, revealed that GFP was discontinuous within the phloem cells of the root (cf. Fig. 5A and $\mathrm{C}$ ). This pattern is consistent with the delivery of BDMVGFP into the root via phloem long-distance transport as opposed to cell-to-cell movement.

Movement of BDMV-GFP toward the shoot apex was examined by preparing sequential transverse/longitudinal sec- tions along the plant axis at different time points. As previously indicated, by $4 \mathrm{dpi}$, GFP was detected in phloem cells only 1 to $2 \mathrm{~cm}$ above the point of inoculation (Fig. $4 \mathrm{H}$ ). In contrast to the situation observed in roots, longitudinal sections of the hypocotyl tissue taken at 6 dpi revealed a continuous distribution of GFP in cells of the phloem, suggesting that BDMV-GFP infection advanced in the acropetal direction by cell-to-cell movement and/or long-distance transport (via sieve elements). At this same time point, GFP was detected in the phloem cells of the cotyledon-hypocotyl junction (Fig. $5 \mathrm{D}$ ), and the high degree of confinement of BDMV-GFP to companion and phloem parenchyma cells in this region is shown in Figure 5E. Examination of the epicotyl region (stem tissue between the cotyledons and the shoot apex) also revealed the presence of GFP in what appeared to be a continuum of phloem cells (Fig. 5F). By 6 dpi, the infection also had reached the primary leaf node and had extended toward the apex, advancing as far as the protophloem (Fig. 5G). As illustrated in Figure 5G, BDMV-GFP extensively infected the cells of the leaf traces within the node of the primary leaves. GFP fluorescence, and thus BDMV-GFP infection, was never detected in the apical meristem. Systemic spread of BDMV-GFP into the lamina of the primary leaf was also detected at this same time point (Fig. $5 \mathrm{H}-\mathrm{K}$ ). In the petioles of primary leaves, BDMV-GFP appeared to be confined to phloem tissues

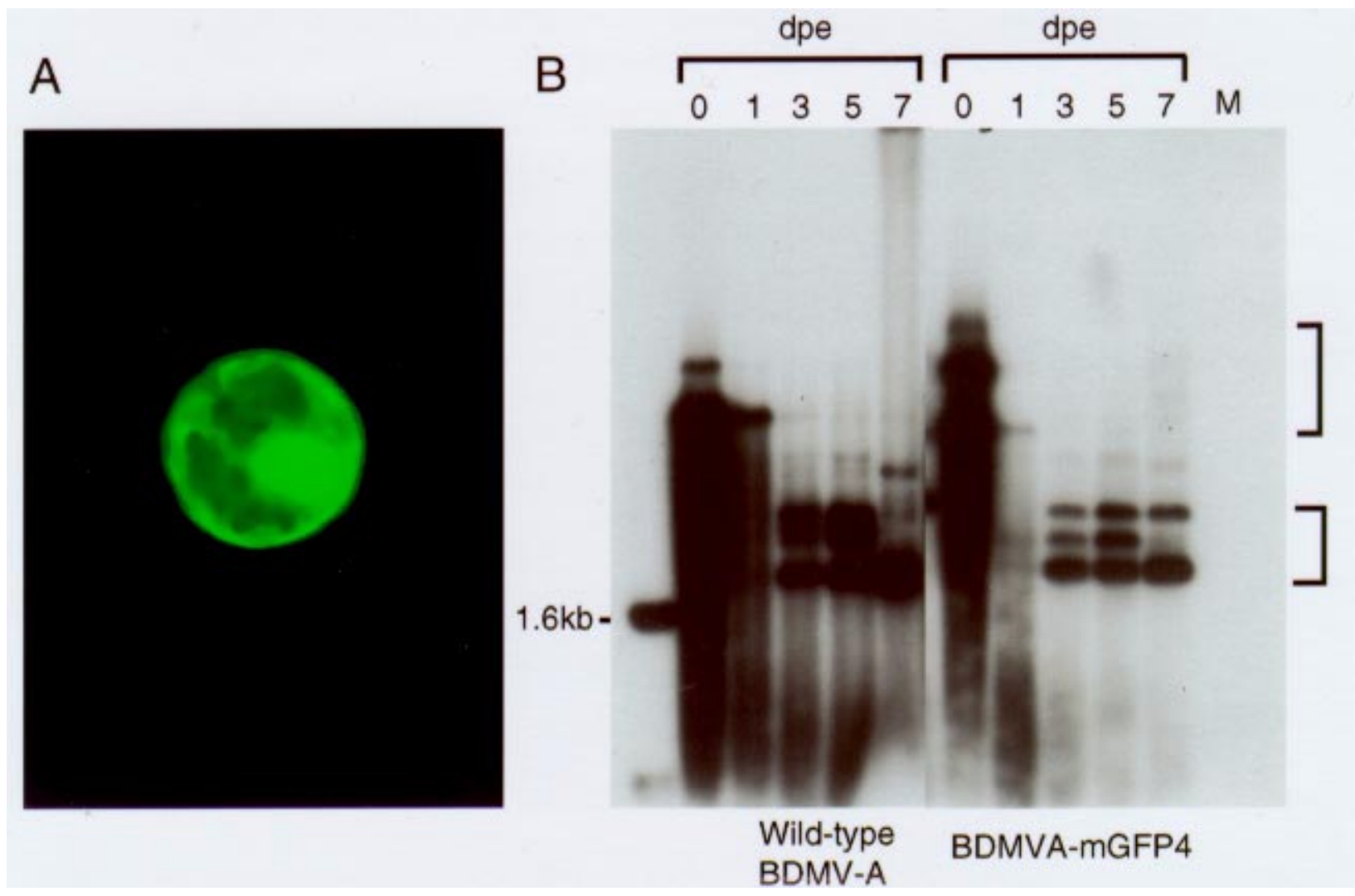

Fig. 2. Analysis of BDMVA-mGFP4 replication and green fluorescent protein (GFP) expression in protoplasts prepared from a Nicotiana tabacum cv. Xanthi nc suspension cell culture. A, GFP fluorescence detected in a protoplast electroporated with the 1.5-mer of BDMVA-mGPF4. Image collected with Sony DKC-500 imaging system attached to a Nikon Microphot SA microscope (magnification $\times 750$ ). B, Southern blot hybridization analysis of total nucleic acids extracted from protoplasts electroporated with 1.5-mers of wild-type BDMV-A or BDMVA-mGFP4 at 0, 1, 3, 5, and 7 days postelectroporation (dpe). Upper bracket (right-hand side) shows input inoculum; lower bracket shows newly replicated viral DNAs. Lane M is total nucleic acids extracted from mock-inoculated protoplasts. Far left lane contains 1-kb ladder (Life Technologies, Grand Island, NY); 1.6-kb fragment is indicated. 

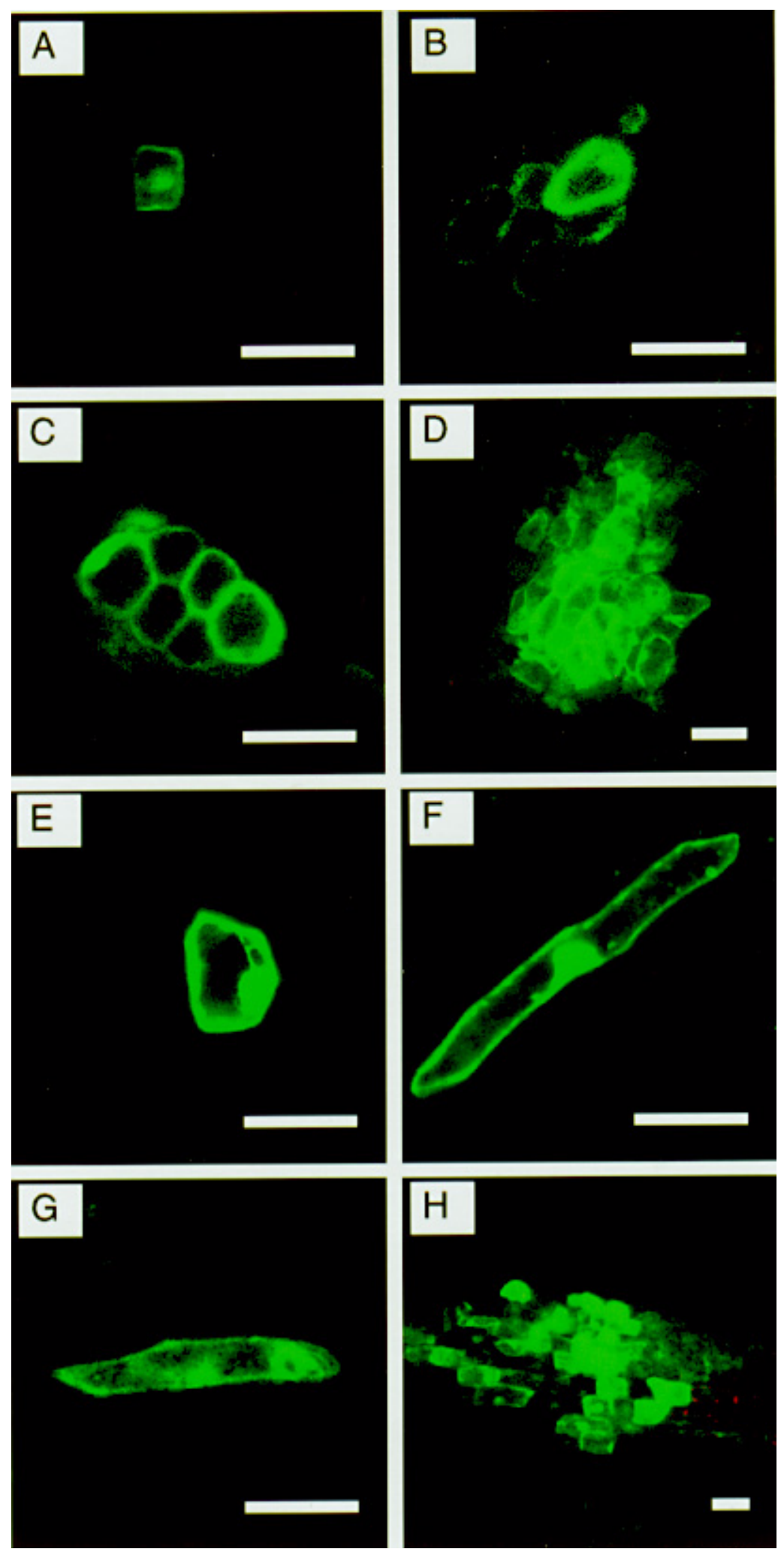

Fig. 3. Confocal laser scanning microscope (CLSM) images of epidermal cells of the hypocotyl of Phaseolus vulgaris cv. Topcrop (common bean) seedlings bombarded with gold particles coated with various bean dwarf mosaic virus (BDMV) constructs. A-D, CLSM images of epidermal cells inoculated with the BDMVA-mGFP4 and BDMV-B components at 12 (A), 16 (B), 24 (C), and 48 (D) h post inoculation (hpi). E-H, CLSM images of epidermal cells collected 48 hpi with BDMVA-mGFP4 alone $(\mathbf{E})$, or together with either a BC1 frameshift mutant $(\mathbf{F})$, a BV1 frameshift mutant $(\mathbf{G})$, or both mutants $(\mathbf{H})$. (Scale bars $=50 \mu \mathrm{m})$ 

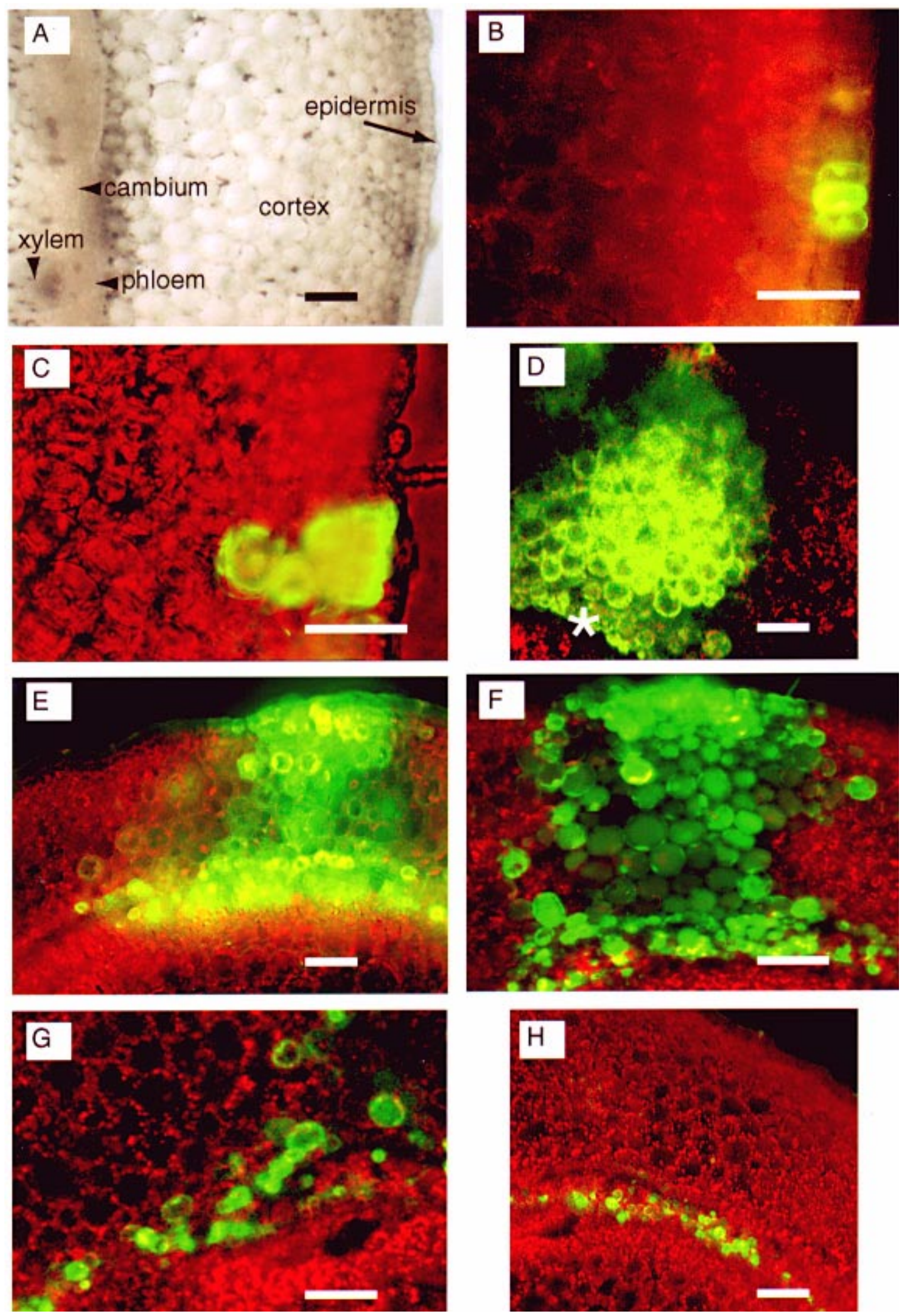

Fig. 4. Bean dwarf mosaic geminivirus-green fluorescent protein (BDMV-GFP) cell-to-cell movement in inoculated region of the bean hypocotyl. A, Transverse section of a bean hypocotyl illustrating the cell types through which BDMV-GFP moved to gain access to the vasculature. B-G, Transverse sections depicting GFP fluorescence in hypocotyl tissues at 18 (B), 24 (C), 48 (D-E) hpi, and 4 days post inoculation (dpi) (F). Asterisk in (D) shows boundary between the cortex and vascular tissue at which viral cell-to-cell movement was temporarily arrested. G, Image of the cortex-vascular boundary located on lower left-hand margin of $\mathbf{F}$. H, Transverse section taken $1 \mathrm{~cm}$ above inoculation site imaged in $\mathbf{F}$. Images presented in $\mathbf{A}-\mathbf{C}$ and $\mathbf{E}$ were obtained with a Nikon fluorescence microscope; images $\mathbf{D}$ and $\mathbf{F}-\mathbf{H}$ represent confocal laser scanning microscope $(\mathrm{CLSM})$ images. (Scale bars $=100 \mu \mathrm{m})$ 
(Fig. 5H). In the primary leaves, GFP fluorescence was detected along veins of all orders (e.g., Fig. 5I and J), and examination of transverse sections of these veins revealed GFP in phloem and mesophyll cells (Fig. 5K). These results suggest that different controls may operate on viral movement within stem/petiole versus leaf tissues.

\section{Influence of plant development on BDMV-GFP leaf infection domains.}

Insight into the relationship between BDMV-GFP phloem and mesophyll infection domains and the influence of plant development was provided by examination of plants infected with BDMV-GFP from the seedling to the flowering and podfill stages of development. In the seedling stage, BDMV-GFP extensively infected primary and, later, newly emerging trifoliolate leaves. In primary leaves, infections occurred within the tissues of all vein orders (i.e., first- through fifth-order) and apparently at random but discrete locations (Fig. 5I and J). In infected primary and trifoliolate leaves of seedlings, the presence of BDMV-GFP was readily detected with the UV lamp, and CLSM was used to identify the infected cell types. As illustrated in Figure 6A, BDMV-GFP infection was detected in both the phloem and mesophyll cells of the primary leaves at 6 dpi. At $18 \mathrm{dpi}$, GFP fluorescence in the primary leaves was still detectable with both the UV lamp and CLSM surface imaging. However, the intensity of GFP (Fig. 6B) as well as the number of plants showing GFP fluorescence in primary leaves, as detected with the UV lamp, was considerably reduced (see also Figure 7). Interestingly, at this same time point, the developing trifoliolate leaves (second and third) examined with the UV lamp and CLSM surface imaging did not show GFP fluorescence (Fig. 6C). However, examination of transverse sections of these same leaves revealed GFP in cells associated with the veins, which suggested that BDMV-GFP was confined to these cells (Fig. 6D). As shown by the data presented in Figure 7, the confinement of BDMVGFP to the phloem of trifoliolate leaves began prior to flowering and was greatest around flower initiation. However, as
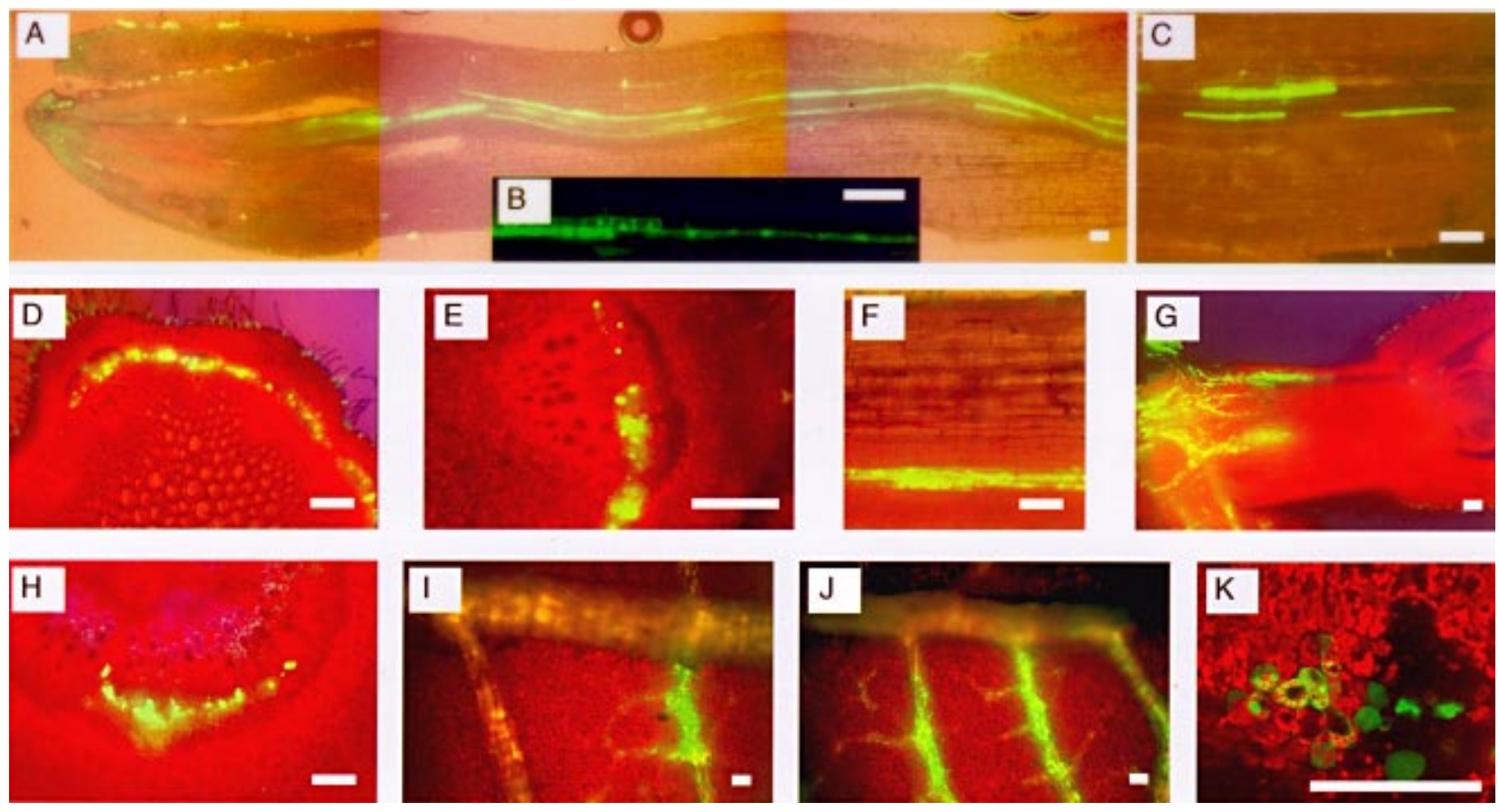

Fig. 5. Spatial distribution of bean dwarf mosaic geminivirus-green fluorescent protein (BDMV-GFP) infection in root, stem, and primary leaf tissues. A, Tissue squash of an infected bean root tip located $11 \mathrm{~cm}$ from inoculation point (5 days post inoculation [dpi]). Examination of uninfected control roots established that the weak fluorescence associated with the root cap and surface represents autofluorescence. B, High magnification image of root companion cells from A. C, Tissue squash prepared from a root section taken $4 \mathrm{~cm}$ back from the root tip $(5 \mathrm{dpi})$. D and E, Transverse section taken just above point of attachment of the cotyledons to the hypocotyl ( $6 \mathrm{dpi}$; there is autofluorescence at base of trichomes). E represents a higher magnification image of the left-most infected vascular bundle in D. F, Longitudinal section of the epicotyl just beneath point of attachment of the primary leaves (6 dpi). G, Longitudinal section through the primary leaf node-shoot apex (6 dpi). GFP is absent from the apical meristem and emerging trifoliolate leaves. $\mathbf{H}$, Transverse section of a primary leaf petiole ( $6 \mathrm{dpi})$. I and J, Primary leaf lamina showing GFP in the minor veins ( 6 dpi). K, Transverse section of a primary leaf at site of a third-order vein $(6 \mathrm{dpi})$. Chlorophyll fluorescence is absent from the phloem and xylem tissue. Images presented in A-J were obtained with a Nikon fluorescence microscope; $\mathbf{K}$ is a confocal laser scanning microscope (CLSM) image. (Scale bars $=100 \mu \mathrm{m})$

Fig. 6. Influence of plant development on bean dwarf mosaic geminivirus-green fluorescent protein (BDMV-GFP) distribution within leaf tissues. A, Confocal laser scanning microscope (CLSM) image of a transverse section of a primary leaf (6 days post inoculation [dpi]). B and C, CLSM images collected in the plane of (B) the primary leaf lamina and (C) a developing trifoliolate leaf, in the region of the vascular tissue (surface scans; $18 \mathrm{dpi}$ ). D, CLSM image of a transverse section taken from the same trifoliolate leaf imaged in C. E, CLSM image collected in the plane of a developing trifoliolate leaf in the region of the vascular tissue (surface scan; $35 \mathrm{dpi}$ ). F, CLSM image of a transverse section taken from the same trifoliolate leaf imaged in E. G, CLSM image collected in the plane of a developing trifoliolate leaf in the region of the vascular tissue (surface scan; $60 \mathrm{dpi}$ ). H, CLSM image of a transverse section taken from the same trifoliolate leaf imaged in G. $($ Scale bars $=100 \mu \mathrm{m}$ ) 

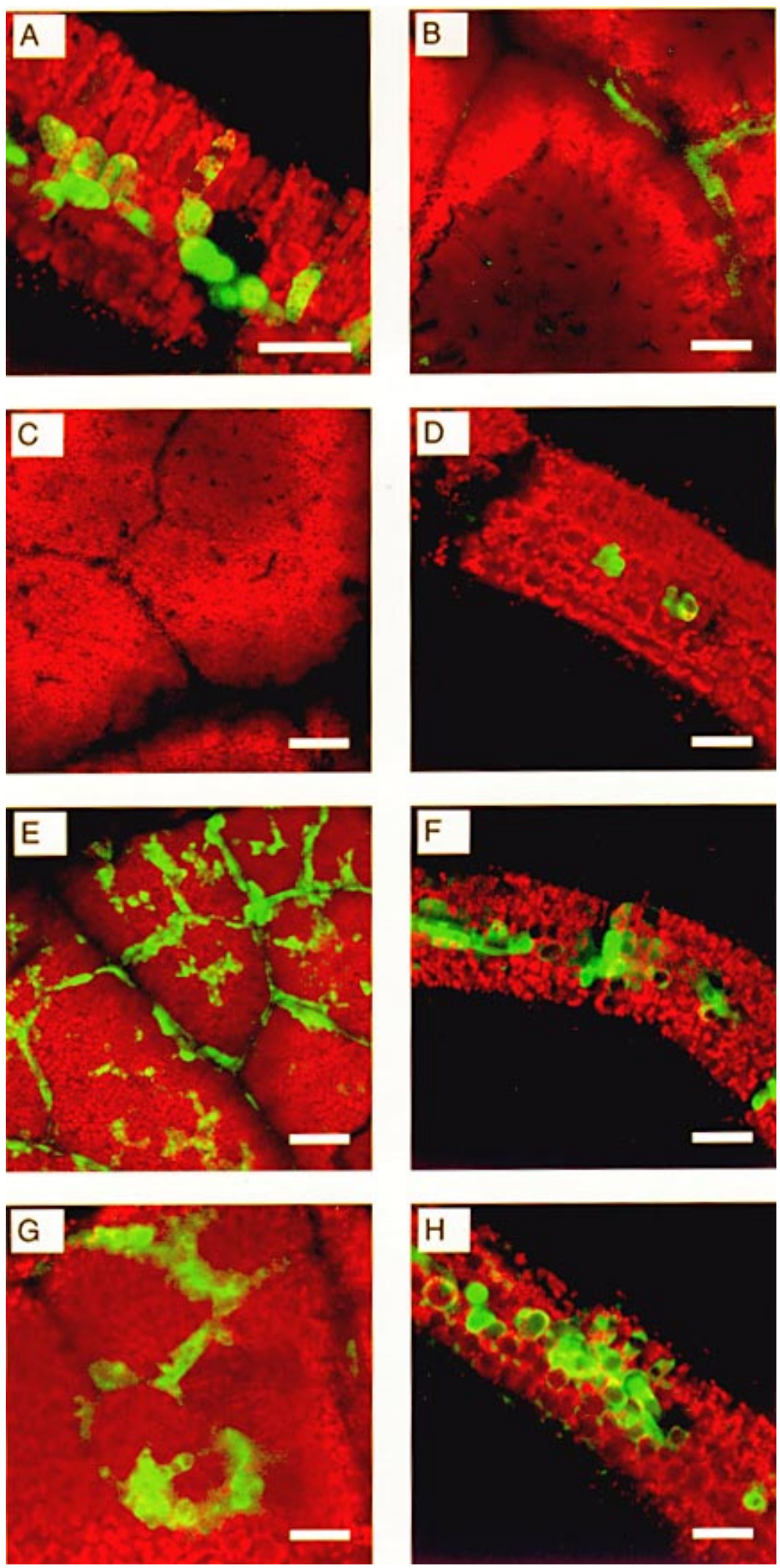
infected bean plants advanced through the flowering phase of development, GFP fluorescence was again detected in newly emerged trifoliolate leaves when examined with the UV lamp and CLSM surface imaging methods (Fig. 6E and F, Fig. 7). Examination of transverse sections of these leaves established that BDMV-GFP was no longer restricted to the phloem, because GFP was again detected in mesophyll cells (Fig. 6F). This pattern of infection (i.e., the release of the confinement of BDMV-GFP from cells of the phloem) in trifoliolate leaves continued through pod fill and beyond (Fig. 6G and H, and Fig. 7).

\section{BDMV-GFP distribution in reproductive organs.}

BDMV-GFP-infected plants consistently showed GFP fluorescence in the flowers, and GFP was readily detected in petal tissues with the UV lamp. Examination of GFP fluorescence in flowers at various stages of development revealed that BDMV-GFP was in the phloem tissues of the flower (Fig. $8 \mathrm{~A}-\mathrm{C})$, extending into the style. As plants continued to develop and set pods, areas of GFP fluorescence were readily detected in pods examined with the UV lamp. Extensive CLSM examination of transverse sections of pods at various stages of maturity revealed the presence of GFP in vascular and inner and outer parenchyma tissues of the pod wall (Fig. 8D). BDMV-GFP was found to extensively infect the outer parenchyma cells of the pod wall (Fig. 8D), which explains the strong fluorescence detected in pods when observed with the UV lamp. Analysis of developing seeds revealed the pres- ence of GFP throughout the vascular tissue, indicating that BDMV-GFP had the capacity to invade the seed coat (Fig. 8E and F). However, in all seeds examined, GFP was never detected in embryonic tissues (cotyledon and embryo). These findings indicated that BDMV-GFP was able to infect maternal tissues of the bean seed, but was excluded from the embryo. These results are consistent with the observation that geminiviruses are not seed transmitted (Mink 1993).

\section{DISCUSSION}

In this study, we followed cell-to-cell and long-distance movement of the bipartite geminivirus, BDMV, throughout the entire life cycle of its natural host, common bean. The basis of these studies was the use of GFP as a noninvasive reporter of viral infection in plant tissues, which represents one of the first examples of using this reporter gene to follow the movement of a DNA virus. The $m G F P 4$ gene, in which the codon usage of the original GFP gene was modified to silence a cryptic intron, was utilized in order to avoid potential aberrant RNA processing (splicing) of the GFP mRNA in plants as reported for Arabidopsis thaliana plants transformed with this gene (Haseloff et al. 1997). To insert the $m G F P 4$ gene into the BDMV genome, we took advantage of the fact that the CP of $\mathrm{BDMV}$, like that of other bipartite geminiviruses, is not essential for systemic infection of adapted hosts (Azzam et al. 1994; Gardiner et al. 1988; Ingham et al. 1995; Padidam et al. 1995; Sudarshana et al. 1996). Moreover, in addition to the

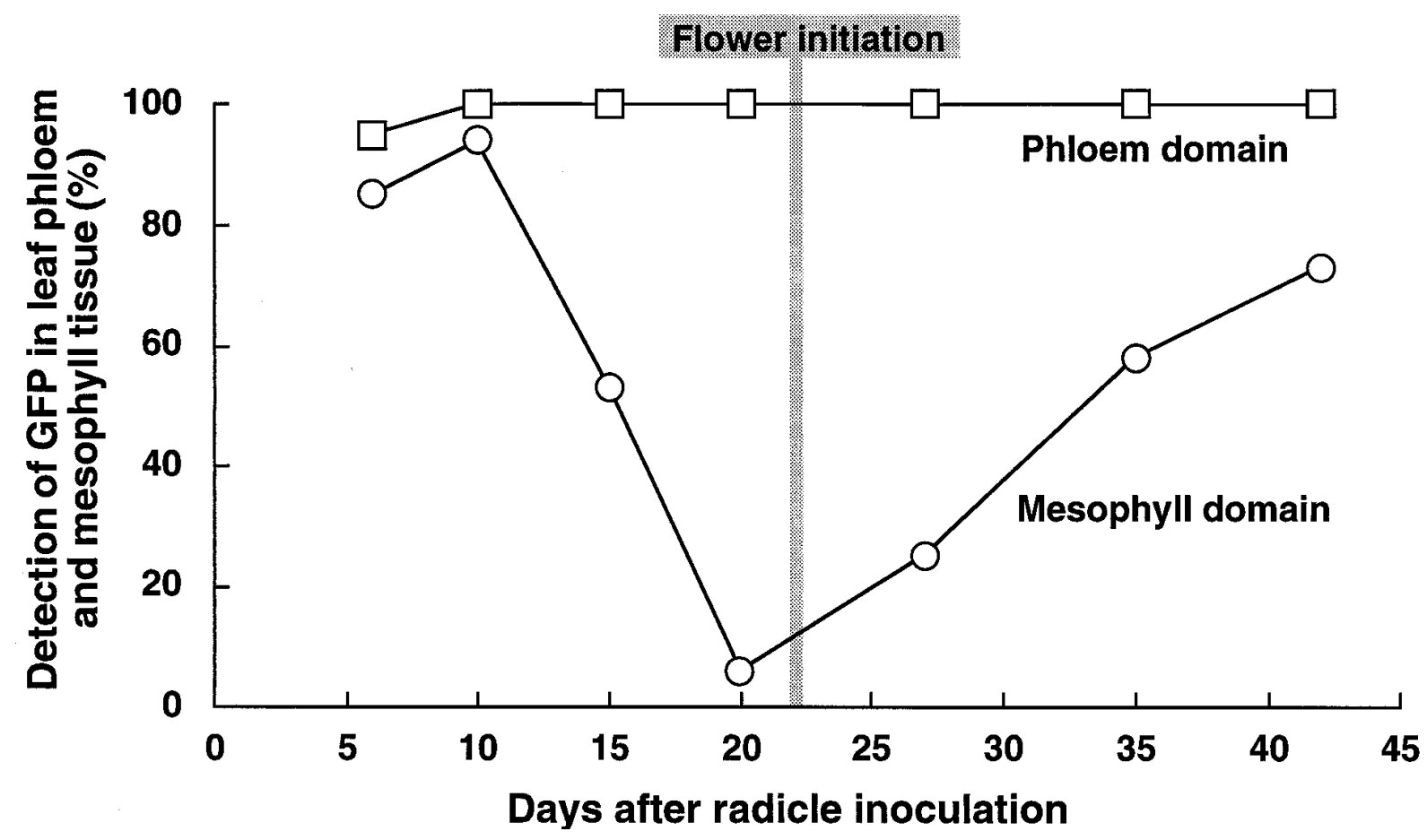

Fig. 7. Time course analysis of the distribution of bean dwarf mosaic geminivirus-green fluorescent protein (BDMV-GFP) in mesophyll and phloem tissue within infected common bean trifoliolate leaves. Data for GFP detection in the phloem and mesophyll domains were obtained by confocal laser scanning microscope (CLSM) examination of transverse sections prepared from expanding trifoliolate leaves; data for the mesophyll domain were also collected with a long-wavelength UV lamp. Data presented represent the percentage of occasions when GFP was detected in cells of the phloem and mesophyll (open circles) as opposed to the occasions when GFP was only detected in phloem tissue (open squares). At the respective time points, the following numbers of plants were examined: 6 days post inoculation (dpi), 21 plants; 10 dpi, 17 plants; 15 dpi, 17 plants; 20 dpi, 17 plants; 27 dpi, 12 plants; 35 dpi, 12 plants; and 42 dpi, 11 plants. Approximately 80 transverse sections were examined per time point. 
autofluorescent property of the GFP protein, the $m G F P 4$ gene is an ideal reporter gene for the bipartite geminiviruses because it is nearly equivalent in size to the $C P$ gene (the $m G F P 4$ gene is 717 bp whereas the BDMV $C P$ gene is 756 bp), which allows the $m G F P 4$ gene to be inserted in place of the $C P$ gene without substantially altering the size of the DNA-A genome. This is critical because significant size increases in the bipartite geminivirus genome lead to recombination and a restoration of normal genome size (Elmer and Rogers 1990; Etessami et al. 1989).
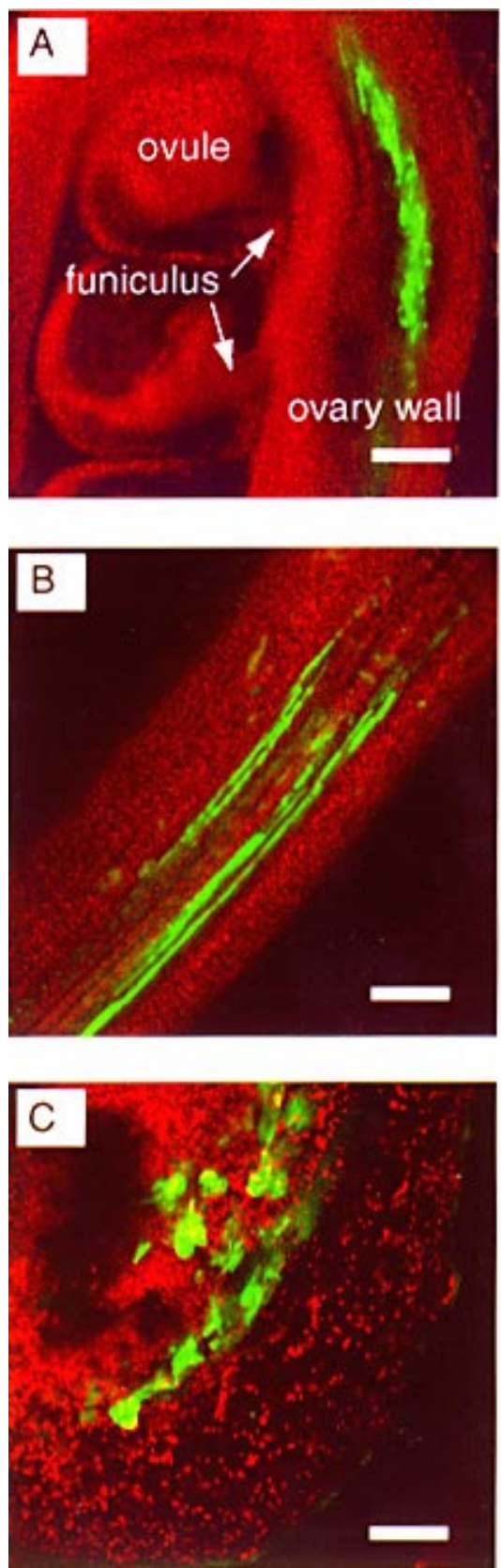

The expression of the $m G F P 4$ gene from BDMVA-mGFP4 throughout the life cycle of the bean plant established that the gene was efficiently expressed from the $\mathrm{CP}$ promoter and stably maintained within the BDMV genome. These results also clearly demonstrate that the $\mathrm{CP}$ is dispensable for BDMV systemic infection of common bean. Recent studies have established a role for the $\mathrm{CP}$ in systemic spread of bipartite geminiviruses in nonadapted hosts (Pooma et al. 1996). The fact that BDMV-GFP induced slightly attenuated symptoms in infected bean plants, compared with wild-type BDMV, sug-
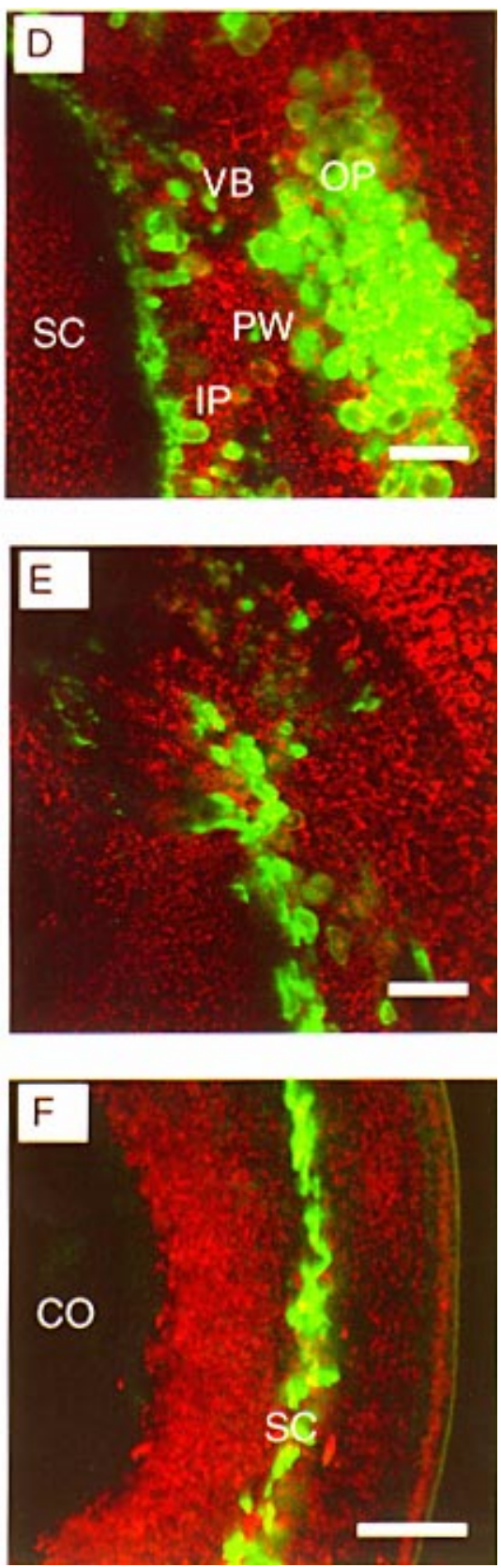

Fig. 8. Detection of bean dwarf mosaic geminivirus-green fluorescent protein (BDMV-GFP) in reproductive tissues. A-C, Longitudinal sections through the ovary (A), petal (B), and connective tissue at the base of the petal (C), all taken from the same flower at 32 days post inoculation (dpi). D, Transverse section of a bean pod taken at $35 \mathrm{dpi}$, with location of section identified according to the GFP fluorescence detected with long-wavelength UV lamp. E and $\mathbf{F}$, Transverse section of bean seed coat $(\mathbf{E})$ near the funiculus, taken at $35 \mathrm{dpi}$, and $(\mathbf{F})$ near the distal end of the seed, taken at $35 \mathrm{dpi}$. During sectioning, the cotyledon was dislodged from the seed, but examination of these cotyledons revealed an absence of GFP. Abbreviations are as follows: CO, area occupied by cotyledon; IP, inner parenchyma; OP, outer parenchyma; PW, pod wall; SC, seed coat; VB, vascular bundle. (Scale bars = $100 \mu \mathrm{m})$ 
gests that the $\mathrm{CP}$ is, at least, a BDMV pathogenicity determinant. However, as the results obtained for BDMV-GFP were similar (in terms of time of virus detection and tissue distribution for comparable stages of plant development) to those obtained in a recent immunolocalization study conducted with wild-type BDMV-infected bean plants (Wang et al. 1996), the role of the $\mathrm{CP}$ in the BDMV infection process per se is probably minimal.

Particle bombardment experiments conducted with BDMVA-mGFP4 provided new insight into the properties of this inoculation method for bean-infecting geminiviruses, as well as the cell-to-cell movement properties of BDMV. The restriction of BDMVA-mGFP4 to single epidermal cells of bombarded bean hypocotyls established that this method delivers gold particles only into the first cell layer of this tissue. This result indicates that the success of this method for infecting beans with bipartite geminiviruses is not due to direct introduction of viral DNA into vascular cells (Gilbertson et al. 1991), but must reflect the capacity for cell-to-cell movement (at least in cells of the hypocotyl). This was clearly demonstrated with BDMV-GFP, which efficiently moved cell to cell in bean hypocotyl tissue. These results provide further evidence of the capacity of this bipartite geminivirus to move in nonphloem cells, and also support our earlier studies in which microinjection of mesophyll cells was used to establish the function of the BDMV BV1 and BC1 proteins (Noueiry et al. 1994).

The finding that the BDMV DNA-A component is incapable of facilitating its own cell-to-cell movement suggests that the $\mathrm{CP}$ does not function as a cell-to-cell MP (i.e., through a direct interaction with plasmodesmata). This finding suggests that the ability of BDMV DNA-A to systemically infect plants when delivered by agroinoculation is independent of viral-mediated, cell-to-cell movement, possibly due to direct introduction of viral DNA into phloem cells (Hou et al. 1998). The mechanism by which the CP facilitates systemic infections of bipartite geminiviruses in nonadapted hosts may involve an aspect(s) of long-distance movement. The restriction of BDMVA-mGFP4 to single cells, when coinoculated with $\mathrm{BC} 1$ or $\mathrm{BV} 1$ frameshift mutants, provides direct experimental evidence for the essential role of both genes (and gene products) in BDMV-GFP cellto-cell movement, and clearly demonstrated it is at this level that the infection process is blocked for these mutants. Similar results were recently reported for TGMV (Jeffrey et al. 1996). The ability of wild-type BDMV DNA-A to facilitate limited cell-to-cell movement of BDMVA-mGFP4 when coinoculated with the BV1 mutant, which provides a functional $\mathrm{BC} 1$ protein, suggests that the $\mathrm{CP}$ may possess nuclear export properties such as those established for the BDMV and SqLCV BV1 proteins (Noueiry et al. 1994; Ingham et al. 1995; Sanderfoot and Lazarowitz 1996). However, the limited cell-to-cell movement observed in this case likely reflects an inefficiency in the capacity of the CP to mediate in DNA export to the cytoplasm.

The cell-to-cell movement of BDMVA-mGFP4, when coinoculated with both frameshift mutants, suggests that complementation, in trans, or a recombination event, occurred between the two frameshift mutants in the inoculated epidermal cells. The finding that the BGMV-GA BC1 and BV1 proteins facilitated the limited cell-to-cell movement of
BDMVA-mGFP4 indicates that the BGMV-GA MPs are not virus specific, which is consistent with results of studies with other Western Hemisphere bipartite geminiviruses (Frischmuth et al. 1993; Schaffer et al. 1995; Hou and Gilbertson 1996). Presumably, the limited cell-to-cell spread of BDMVAmGFP4 reflects the transient expression of the BGMV-GA $\mathrm{BC} 1$ and $\mathrm{BV} 1$ proteins in the absence of BGMV-GA DNA-B replication.

The differences in the pattern of BDMV-GFP systemic infection in roots versus shoots likely reflect the regulation of photoassimilate partitioning in these organs. Nutrient delivery into developing Arabidopsis thaliana root tissue appears to occur in a wave that takes place immediately behind the zone of phloem differentiation (Oparka et al. 1994). Presuming that a similar pattern occurs within the common bean root, the exit of the infectious form of BDMV-GFP from the phloem may be confined to a similar zone within the unloading region of the root. The discontinuous pattern of GFP within the root vascular tissue is consistent with the delivery of BDMV-GFP via the phloem translocation stream (i.e., long-distance transport). The fact that BDMV-GFP infected only a limited number of root phloem cells, and was unable to egress into surrounding tissues, likely reflects the inability of the BDMV MPs to mediate cell-to-cell transport of BDMV-GFP DNA from these cell types. In contrast, the continuous distribution of GFP from the site of inoculation to the shoot apex was consistent with the involvement of both cell-to-cell movement and long-distance transport mechanisms. The relatively short time required for the detection of GFP in the shoot apex, following BDMV-GFP arrival at the cotyledonary node, suggests long-distance translocation. Thus, different controls over sieve element-companion cell exchange in root versus stem/shoot apex tissues may influence the exit of the virus from the phloem into these different tissues and, thus, the ultimate distribution of the virus within the plant.

The extensive distribution of GFP within the protophloem of the shoot apex is consistent with our earlier immunolocalization results (Wang et al. 1996). Infection of this tissue has been proposed to play a critical role in the establishment and maintenance of BDMV systemic infection (Gilbertson and Lucas 1996). The fact that GFP was not detected in cells of the apical meristem supports the concept that there is some feature of the plant apex that prevents BDMV from moving from the protophloem to meristematic tissue. The genetic basis for this blockage may be revealed through a search for plant mutants that, upon infection with BDMV-GFP, exhibit an altered GFP distribution in the shoot apex.

Analysis of GFP distribution within systemically infected leaves revealed two significant findings. First, in contrast to the case with stem and petiole tissues, BDMV-GFP was not confined to phloem tissue of the leaf veins in primary or trifoliolate leaves. This may indicate differences in the control of the photoassimilate pathway in sink leaves, reflecting the need to unload nutrients into these rapidly expanding tissues. Interestingly, the pattern of BDMV-GFP infection in sink leaves was different from that recently reported for the GFP-tagged potato virus $\mathrm{X}$ potexvirus infecting Nicotiana benthamiana, in which the virus initiated infection from the third-order veins (Roberts et al. 1997). These differences in the patterns of virus infection within developing leaves may be due to host- and/or viral-associated factors. 
Second, the ability of BDMV-GFP to exit the phloem and infect nonphloem cells in leaves was correlated with the developmental status of the common bean plant. Moreover, this followed a bimodal pattern, with GFP being detected in nonphloem cells early and late in plant development, but not during the active vegetative stage of plant growth prior to and during the transition to flowering. This pattern likely reflects competition, within the plant, for photoassimilates between reproductive organs (flowers and pods) and vegetative tissues (leaves). If this is the case, it demonstrates the influence of plant development on the distribution of BDMV in different tissues. Modulation of floral induction by photoperiod or phytohormones may help elucidate the basis for this phenomenon.

The influence of phloem delivery of photoassimilate on the distribution of BDMV-GFP in various cell and tissue types was further suggested by the extensive GFP fluorescence detected in reproductive tissues, which act as strong sinks. This was particularly evident in tissues of the pods, where BDMVGFP was able to move into the surrounding parenchyma tissue in a manner similar to that observed in leaf lamina in the early and late stages of plant development. This may reflect the common ontogenic origin of these two organs. The inability of BDMV-GFP to infect embryonic tissues may reflect structural and/or regulatory boundaries associated with the early stages of embryo development. The presence of BDMV-GFP in the seed coat late in seed development also likely reflects its efficient delivery during the strong sink activity associated with this tissue but, because of the lack of symplasmic continuity between the tissues of the seed coat and the embryo, BDMVGFP is restricted to the maternal tissue. Moreover, as this maternal tissue undergoes desiccation and death (seed coat) during seed maturation, the vertical passage of BDMV to the new seedling is prevented.

Through the use of a noninvasive reporter of viral infection, the infection process of a bipartite geminivirus has been followed from the initial inoculated cells in the seedling to the seed in reproductively mature plants. The precise cell and tissue types infected during the life cycle of the plant have been identified, and this has revealed that the processes underlying plant development greatly influence the viral infection process. Future studies of the bean hypocotyl system should provide further understanding of viral and host factors involved in plasmodesmalmediated, cell-to-cell movement of geminiviruses.

\section{MATERIALS AND METHODS}

\section{BDMV and GFP clones.}

Infectious, full-length clones of BDMV DNA-A (pBDA1) and DNA-B (pBDB1) have been previously described (Gilbertson et al. 1991; Hidayat et al. 1993). The $m G F P 4$ gene, cloned as a BamHI/SacI fragment in pBIN-mGFP4, was kindly provided by J. Haseloff (MRC, Cambridge University). BDMV 1.5-mer clones of DNA-A (pBDA1.5) and DNA-B (pBDB1.5) have been described by Hou et al. (1998). BDMV BC1 (BL1) and BV1 (BR1) frameshift mutants in DNA-B have been described by Noueiry et al. (1994). Monomeric clones having these frameshift mutations were introduced into $\mathrm{pBDB} 1.5$, in place of the wild-type DNA-B clone, to generate pBDBC1fs1.5 and pBDBV1fs1.5 (Y.-M. Hou and R. L. Gilbertson, unpublished results).

\section{Construction of BDMVA-mGFP4 monomeric and 1.5-mer clones.}

A 971-bp ApaI-SalI fragment containing the BDMV CP sequence was subcloned from pBDA1 into $\mathrm{pKS}^{+}$(Stratagene, La Jolla, CA) to generate pBDCP. Oligonucleotide primers and polymerase chain reaction (PCR) were used to amplify the $\mathrm{CP} 5^{\prime}$ noncoding sequence from pBDA1, in order to introduce an SstI site and the sequence of the first four codons of the mGFP4 gene (Fig. 1C). Another set of primers and PCR were used to amplify the CP 3 ' noncoding sequence from $\mathrm{pBDCP}$ in order to introduce an $S s t \mathrm{I}$ site upstream of the CP termination codon (Fig. 1D). These PCRamplified fragments were cloned with the TA cloning system (Invitrogen, San Diego, CA) to generate pBDACP5 and pBDACP3, respectively, and sequenced to confirm their identity.

The $m G F P 4$ gene was excised from pBIN-mGFP4 as a BamHI-EcoRI fragment, and subcloned into $\mathrm{pKS}^{+}$to generate pKSmGFP4. The $m G F P 4$ gene in pKSmGFP4 was then modified by PCR-based, site-directed mutagenesis in order to introduce two silent mutations into the $5^{\prime}$ end of the gene, thus creating an SstI site (Fig. 1C). This PCR-amplified fragment was then purified, digested with $S s t \mathrm{I}$, and subcloned into SstIdigested $\mathrm{pKS}^{+}$to generate $\mathrm{pKSmGFP} 4 \mathrm{~A}$. The sequence of the $5^{\prime}$ end of the modified $m G F P 4$ gene clone in pKSmGFP4A was verified by sequencing and then the $3^{\prime}$ portion of the gene in pKSmGFP4A was exchanged as an NcoI-EcoRI fragment with the corresponding sequence from pKSmGFP4 to generate $\mathrm{pKSmGFP4B.}$

To facilitate the fusion of the PCR-amplified BDMV DNAA fragments with the modified mGFP4 sequence, the SstI site in $\mathrm{pKS}^{+}$was silenced by digesting the vector with $S s t \mathrm{I}-X b a \mathrm{I}$, blunting the ends with T4 DNA polymerase, and self-ligating to generate pKS-XS $\Delta$. The PCR clone containing the CP $3^{\prime}$ noncoding sequence was released from pBDCP3 by digestion with EcoRI, and cloned into EcoRI-digested pKS-XS $\Delta$ to generate pKS-CP3. A BamHI-SacI fragment containing the $\mathrm{CP} 5^{\prime}$ noncoding sequence was released from pBDCP5 and ligated with BamHI-SacI-digested pKS-CP3 to generate pKSCP53. pKS-CP53 was linearized by digestion with SstI, dephosphorylated, and ligated with the SstI fragment released from pKSmGFP4B to generate pKSmGFP4C. The mGFP4 fragment from $\mathrm{pKSmGFP} 4 \mathrm{~B}$, which lacked the sequence corresponding to the first four codons of the $m G F P 4$ gene, had this sequence restored from the $3^{\prime}$ end of the BDCP5 fragment. After the correct orientation of the mGFP4 gene in pKSmGFP4C was verified, the ApaI-SalI fragment containing the $\mathrm{CP} 5^{\prime}$ and $3^{\prime}$ noncoding sequences and the $m G F P 4$ gene was released from $\mathrm{pKSmGFP4C}$ and inserted in place of the corresponding ApaI-SalI fragment in pBDA1 to generate pBDMVA-mGFP4 (Fig. 1B).

A 1.5-mer clone of pBDMVA-mGFP4 was generated by releasing a 1-kb SalI fragment from pBDMVA-mGFP4 and self-ligating the remaining BDMVA-mGFP4 plasmid to generate pBDMVA-mGFP4S. This recombinant plasmid was linearized at the unique $B g l \mathrm{II}$ site (nucleotide 2256 in BDMVA), and ligated with the monomer of the BDMVA-mGFP4 fragment released from pBDMVA-mGFP4 to generate pBDMVA-mGFP1.5. This construct contained 1.5 copies of the BDMVA-mGFP4 construct, with a single copy of the $m G F P 4$ gene. 


\section{Preparation of protoplasts and assays for viral replication and GFP expression.}

Protoplasts were prepared from Nicotiana tabacum cv. Xanthi nc cell suspension cultures as previously described (Paplomatas et al. 1994). For each construct to be tested, 10 $\mu \mathrm{g}$ of DNA was electroporated into approximately $4 \times 10^{6}$ protoplasts at $290 \mathrm{~V}$ and $490 \mu \mathrm{F}$ for $8 \mathrm{~ms}$. Transfected protoplasts were kept in the dark at room temperature and samples were removed at $0,1,3,5$, and 7 days postelectroporation. DNA was extracted from cells as previously described (Paplomatas et al. 1994), and analyzed by Southern blot hybridization with a ${ }^{32} \mathrm{P}$-labeled $\mathrm{pBDA} 1$ probe as previously described (Hou et al. 1998). GFP expression was detected with a Nikon Microphot SA microscope (Nikon, Melville, NY).

\section{Particle bombardment.}

Germinating common bean seedlings (cv. Topcrop) were bombarded with gold particles coated with various DNA preparations, with a PDS-1000 particle acceleration device (Du Pont, Wilmington, DE) as described by Paplomatas et al. (1994). To restrict the zone of bombardment to radicle and hypocotyl tissues, cotyledons were covered with two layers of aluminum foil. Inoculated seedlings were planted in soil in pots and maintained in a controlled environment chamber $\left(250 \mu \mathrm{E} \cdot \mathrm{s}^{-1} \cdot \mathrm{m}^{-2}\right.$ photosynthetically active radiation, 16-h photoperiod, $30^{\circ} \mathrm{C}$ day $/ 22^{\circ} \mathrm{C}$ night), unless otherwise noted. Plants were observed for symptoms, and GFP expression was detected with a hand-held, long-wavelength, ultraviolet lamp (UVP, Upland, CA).

\section{Preparation of bean tissue samples for GFP detection.}

Bean plants at different stages of development were carefully removed from pots, and the soil was subsequently washed from the roots. Transverse and longitudinal sections of plant material were prepared by hand with a razor blade. In some cases, tissue squashes were also prepared. Unfixed specimens were mounted in water and GFP fluorescence was detected with a Leica TCS-4D CLSM (Leica Lasertechnik, Heidelberg, Germany) with two-channel scanning. An argon/ krypton laser was used for detection of GFP (488 nm excitation, 507-nm emission filter). For chlorophyll autofluorescence, $568 \mathrm{~nm}$ excitation and a 590-nm emission filter were employed. In some cases, samples were examined with a Nikon Optiphoto-2 photo microscope. Images were directly recorded in TIFF format at a PC workstation. After Macintosh processing of data with Adobe Photoshop 3.0 and generation of pseudocolors (GFP = green to yellow-green, and chlorophyll $=$ red), photographs were printed via a phase 440 laser printer (Tektronix, Wilsonville, OR).

\section{ACKNOWLEDGMENTS}

This research was supported by the U.S. Department of Agriculture National Research Initiative Competitive Grants Program (9500838 to R. L. G. and W. J. L.). We thank J. Haseloff, MRC, England, for providing the mGFP4 gene. We also thank Lauren R. Franssen for assistance with replication assays in protoplasts, K. C. McFarland for excellent technical assistance in image and data preparation and management, and M. R. Rojas for critical review of the manuscript.

\section{LITERATURE CITED}

Azzam, O., Frazer, J., De La Rosa, D., Beaver, J. S., Ahlquist, P., and Maxwell, D. P. 1994. Whitefly transmission and efficient ssDNA accumulation of bean golden mosaic geminivirus require functional coat protein. Virology 204:289-296.

Baulcombe, D. C., Chapman, S., and Santa Cruz, S. 1995. Jellyfish fluorescent protein as a reporter for virus infections. Plant J. 7:1945-1953.

Brough, C. L., Hayes, R. J., Morgan, A. J., Coutts, R. H., and Buck, K. W. 1988. Effects of mutagenesis in vitro on the ability of cloned tomato golden mosaic virus DNA to infect Nicotiana benthamiana plants. J. Gen. Virol. 69:503-514.

Canto, T., Prior, D. A. M., Hellwald, K.-H., Oparka, K. J., and Palukaitis, P. 1997. Characterization of cucumber mosaic virus. IV. Movement protein and coat protein are both essential for cell-to-cell movement of cucumber mosaic virus. Virology 237:237-248.

Carrington, J. C., Kasschau, K. D., Mahajan, S. K., and Schaad, M. C. 1996. Cell-to-cell and long-distance transport of viruses in plants. Plant Cell 8:1669-1681.

Chalfie, M., Tu, Y., Euskirchen, G., Ward, W. W., and Prasher, D. C. 1994. Green fluorescent protein as a marker for gene expression. Science 263:802-805.

Deom, C. M., Oliver, M. J., and Beachy, R. N. 1987. The 30-kilodalton gene product of tobacco mosaic virus potentiates virus movement. Science 237:389-394.

Deom, C. M., Schubert, K. R., Wolf, S., Holt, C. A., Lucas, W. J., and Beachy, R. N. 1990. Molecular characterisation and biological function of the movement protein of tobacco mosaic virus in transgenic plants. Proc. Natl. Acad. Sci. USA 87:3284-3288.

Ding, B., Li, Q. B., Nguyen, L., Palukaitis, P., and Lucas, W. J. 1995. Cucumber mosaic virus 3 a protein potentiates cell-to-cell trafficking of CMV RNA in tobacco plants. Virology 207:345-353.

Elmer, S., and Rogers, S. G. 1990. Selection of wild type derivatives of tomato golden mosaic virus during systemic infection. Nucleic Acids Res. 18:2001-2006.

Epel, B. L., Padgett, H. S., Heinlein, M., and Beachy, R. N. 1996. Plant virus movement protein dynamics probed with a GFP-protein fusion. Gene 173:75-79.

Etessami, P., Callis, R., Ellwood, S., and Stanley, J. 1988. Delimitation of the essential genes of the cassava latent virus DNA 2. Nucleic Acids Res. 16:4811-4829.

Etessami, P., Watts, J., and Stanley, J. 1989. Size reversion of African cassava mosaic virus coat protein gene deletion mutants during infection of Nicotiana benthamiana. J. Gen. Virol. 70:277-289.

Evans, D., and Jeske, H. 1993. DNA B facilitates, but is not essential for, the spread of Abutilon mosaic virus in agroinoculated Nicotiana benthamiana. Virology 194:752-757.

Frischmuth, T., Roberts, S., von Arnim, A., and Stanley, J. 1993. Specificity of bipartite geminivirus movement proteins. Virology 196:666673.

Fujiwara, T., Giesman-Cookmeyer, D., Ding, B., Lommel, S. A., and Lucas, W. J. 1993. Cell-to-cell trafficking of macromolecules through plasmodesmata potentiated by the red clover necrotic mosaic virus movement protein. Plant Cell 5:1783-1794.

Gardiner, W., Sunter, G., Brand, L., Elmer, J. S., Rogers, S. G., and Bisaro, D. M. 1988. Genetic analysis of tomato golden mosaic virus: The coat protein is not required for systemic spread or symptom development. EMBO J. 7:899-904.

Gilbertson, R. L., Faria, J. C., Hanson, S. F., Morales, F. J., Ahlquist, P., Maxwell, D. P., and Russell, D. R. 1991. Cloning of the complete DNA genomes of four bean-infecting geminiviruses and determining their infectivity by electric discharge particle acceleration. Phytopathology 81:980-985.

Gilbertson, R. L., and Lucas, W. J. 1996. How do viruses traffic on the vascular highway? Trends Plant Sci. 1:260-267.

Haseloff, J., Siemering, K. R., Prasher, D. C., and Hodge, S. 1997. Removal of cryptic intron and subcellular localization of green fluorescent protein are required to mark transgenic Arabidopsis plants brightly. Proc. Natl. Acad. Sci. USA 94:2122-2127.

Hidayat, S. H., Gilbertson, R. L., Hanson, S. F., Morales, F. J., Ahlquist, P., Russell, D. R., and Maxwell, D. P. 1993. Complete nucleotide sequences of the infectious cloned DNAs of bean dwarf mosaic geminivirus. Phytopathology 83:181-187.

Hou, Y.-M., and Gilbertson, R. L. 1996. Increased pathogenicity in a 
pseudorecombinant bipartite geminivirus correlates with intermolecular recombination. J. Virol. 70:5430-5436.

Hou, Y.-M., Paplomatas, E. J., and Gilbertson, R. L. 1998. Host adaptation and replication properties of two bipartite geminiviruses and their pseudorecombinants. Mol. Plant-Microbe Interact. 11:208-217.

Ingham, D. J., Pascal, E., and Lazarowitz, S. G. 1995. Both geminivirus movement proteins define viral host range, but only BL1 determines viral pathogenicity. Virology 207:191-204.

Jeffrey, J. L., Pooma, W., and Petty, I. T. D. 1996. Genetic requirements for local and systemic movement of tomato golden mosaic virus in infected plants. Virology 223:208-218.

Klinkenberg, F. A., and Stanley, J. 1990. Encapsidation and spread of African cassava mosaic virus DNA A in the absence of DNA B when agroinoculated to Nicotiana benthamiana. J. Gen. Virol. 71:14091412.

Lucas, W. J., and Gilbertson, R. L. 1994. Plasmodesmata in relation to viral movement in leaf tissues. Annu. Rev. Phytopathol. 32:387-411.

Mink, G. I. 1993. Pollen- and seed-transmitted viruses and viroids. Annu. Rev. Phytopathol. 31:375-402.

Noueiry, A. O., Lucas, W. J., and Gilbertson, R. L. 1994. Two proteins of a plant DNA virus coordinate nuclear and plasmodesmal transport. Cell 76:925-932.

Oparka, K. J., Duckett, C. M., Prior, D. A. M., and Fisher, D. B. 1994. Real-time imaging of phloem unloading in the root tip of Arabidopsis. Plant J. 6:759-766.

Oparka, K. J., Roberts, A. G., Prior, D. A. M., Chapman, S., Baulcombe, D., and Santa Cruz, S. 1995. Imaging the green fluorescent protein in plants - viruses carry the torch. Protoplasma 189:133-141.

Padgett, H. S., Epel, B. L., Kahn, T. W., Heinlein, M., Watanabe, Y., and Beachy, R. N. 1996. Distribution of tobamovirus movement protein in infected cells and implications for cell-to-cell spread of infection. Plant J. 10:1079-1088

Padidam, M., Beachy, R. N., and Fauquet, C. M. 1995. Tomato leaf curl geminivirus from India has a bipartite genome and coat protein is not essential for infectivity. J. Gen. Virol. 76:25-35.

Paplomatas, E. J., Patel, V. P., Hou, Y.-M., Noueiry, A. O., and Gilbertson, R. L. 1994. Molecular characterization of a new saptransmissible bipartite genome geminivirus infecting tomatoes in Mexico. Phytopathology 84:1215-1224.

Pooma, W., Gillette, W. K., Jeffrey, J. L., and Petty, I. T. D. 1996. Host and viral factors determine dispensability of coat protein for bipartite geminivirus systemic movement. Virology 218:264-268.

Rao, A. L. N. 1997. Molecular studies on bromovirus capsid protein. III. Analysis of cell-to-cell movement competence of coat protein defective variants of cowpea chlorotic mottle virus. Virology 232:385-395.

Roberts, A. G., Santa Cruz, S., Roberts, I. M., Prior, D. A. M., Turgeon, R., and Oparka, K. J. 1997. Phloem unloading in sink leaves of Nicotiana benthamiana: Comparison of a fluorescent solute with a fluorescent virus. Plant Cell 9:1381-1396.

Rojas, M. R., Zerbini, F. M., Allison, R. F., Gilbertson, R. L., and Lucas, W. J. 1997. Capsid protein and helper component proteinase function as potyvirus cell-to-cell movement proteins. Virology 237:283-295.

Samuel, G. 1934. The movement of tobacco mosaic virus within the plant. Ann. Appl. Biol. 21:90-111.

Sanderfoot, A. A., and Lazarowitz, S. G. 1996. Getting it together in plant virus movement: Cooperative interactions between bipartite geminivirus movement proteins. Trends Cell Biol. 6:353-358.

Santa Cruz, S., Chapman, S., Roberts, A. G., Roberts, I. M., Prior, D. A. M., and Oparka, K. J. 1996. Assembly and movement of a plant virus carrying a green fluorescent protein overcoat. Proc. Natl. Acad. Sci. USA 93:6286-6290.

Schaffer, R. L., Miller, C. G., and Petty, I. T. D. 1995. Virus and hostspecific adaptations in the BL1 and BR1 genes of bipartite geminiviruses. Virology 214:330-338.

Séron, K., and Haenni, A. L. 1996. Vascular movement of plant viruses. Mol. Plant-Microbe Interact. 9:435-442.

Sudarshana, M. R., Wang, H. L., Hou, Y.-M., Noueiry, A. O., Lucas, W. J., and Gilbertson, R. L. 1996. Expression of green fluorescent protein by a coat protein deficient DNA A component of bean dwarf mosaic geminivirus. (Abstr.) Phytopathology 86:S45.

Waigmann, E., Lucas, W. J., Citovsky, V., and Zambryski, P. 1994. Direct functional assay for tobacco mosaic virus cell-to-cell movement protein and identification of a domain involved in increasing plasmodesmal permeability. Proc. Natl. Acad. Sci. USA 91:1433-1437.

Wang, H. L., Gilbertson, R. L., and Lucas, W. J. 1996. Spatial and temporal distribution of bean dwarf mosaic geminivirus in Phaseolus vulgaris and Nicotiana benthamiana. Phytopathology 86:1204-1214.

Wolf, S., Deom, C. M., Beachy, R. N., and Lucas, W. J. 1989. Movement protein of tobacco mosaic virus modifies plasmodesmal size exclusion limit. Science 246:377-379. 